\title{
Gurias Digitais: Inclusão de Meninas na Área de TI
}

\author{
Amanda Righês Saccol, Carla Lisiane de Oliveira Castanho, Eduardo Ferreira da \\ Silva, Eduardo Henrique Spies, Victor Machado Alves
}

Departamento de Engenharias e Ciência da Computação - Universidade Regional Integrada do Alto Uruguai e das Missões (URI Câmpus Santiago)

Caixa Postal 181 - 97.700-000 - Santiago, RS - Brasil

amandarighess@gmail.com, \{carla.castanho, eduardo.ferreira,

eduardo.spies, victor.alves\}@urisantiago.br

\begin{abstract}
The IT area is constantly advancing, but the low participation of women is becoming increasingly alarming. This work aims to analyze the participation of women in the computational area and to report the development of the Gurias Digitais project, which seeks to encourage girls from a municipal school in the city of Santiago to better understand the area of Computing, also encouraging them to consider the area as a valid career option, teaching them how to develop their own game.
\end{abstract}

Resumo. A área de TI encontra-se em constante avanço, mas a baixa participação das mulheres vem se tornando cada vez mais alarmante. Esse trabalho objetiva analisar a participação da mulher na área computacional e relatar o desenvolvimento do projeto Gurias Digitais, o qual busca incentivar meninas de uma escola municipal da cidade de Santiago a conhecer melhor a área da Computação, também as incentivando a considerar a área como uma opção de carreira válida, ensinando-as a desenvolver seu próprio jogo.

\section{Introdução}

Tanto nas salas de aulas das universidades, quanto nos setores mais técnicos das grandes empresas de Tecnologia da Informação (TI), as mulheres são sempre minoria. Mesmo estando acostumadas a invenções inovadoras e muitas vezes revolucionárias, as empresas gigantes da área parecem incapazes de resolver uma questão tão antiga quanto urgente: a baixa participação das mulheres em seu quadro funcional. Por exemplo no Google, 30\% dos funcionários são mulheres, mas se levarmos em conta a divisão de engenharia, a relação fica ainda menor, ficando em torno de 17\%. Não é um problema isolado, a mesma relação de desigualdade entre homens e mulheres acontece no Facebook, onde apenas 31\% são mulheres, na Apple e no Twitter este número fica abaixo de 30\% [Felitti, 2015].

Deste modo, esse trabalho busca averiguar a situação encontrada dentro do ambiente escolar da cidade de Santiago, situada no estado do Rio Grande do Sul, focando no desenvolvimento do projeto Gurias Digitais aplicado em uma escola municipal, verificando o interesse das alunas dos anos finais do ensino fundamental pela possível participação e inclusão na Computação. Onde, através do desenvolvimento de jogos, tornará possível o desenvolvimento inicial da lógica de programação, buscando 
despertar e fomentar o interesse pela área, estimulando a criatividade e a tomada de decisões.

\section{Mulheres na Computação}

De acordo com a história, o estudo das ciências se caracteriza como sendo uma incumbência masculina, mesmo as mulheres buscando estarem presentes no aperfeiçoamento das mesmas. Mulheres de primordial relevância para a evolução tecnológica, como Ada Lovelace, Mary Kenneth Keller, Grace Hopper, Dana Ulery, Hedy Lamarr e Kathleen Antonelli são nomes dos quais poucas pessoas já ouviram falar. Em contrapartida, Steve Jobs, Bill Gates e Mark Zuckerberg são conhecidos por praticamente todo mundo. Segundo Oliveira, Moro e Prates (2014), "mesmo quando uma mulher (ou um grupo de mulheres) teve importância vital na história científica, a sua participação foi completamente apagada ou ignorada nos registros dos fatos", como exemplo a criação do primeiro computador ou das primeiras linguagens de programação.

$\mathrm{Na}$ ocorrência de algum problema, "o menino da informática" é lembrado para resolver, ou "o programador" quando o sistema sofre alguma queda, ou ainda "o cara" que trabalha em campo. A identidade do profissional da Computação é inconscientemente entendida como masculina, mesmo as mulheres sendo igualmente capazes de realizar as mesmas tarefas. Analisando a diferença de gênero em termos de potencial e capacidades intelectuais não existem, ressaltando que podem haver bons e maus profissionais independente de questões gênero [Oliveira et al., 2016].

\subsection{Meninas Digitais}

Como tentativa de aumentar a proporção de mulheres na área de TI, a Sociedade Brasileira de Computação (SBC), chancelou em 2011 o Programa Meninas Digitais, recebendo sua chancela como programa de interesse nacional da comunidade da computação, direcionado a criação de ações voltadas a alunas do Ensino Médio/Tecnológico e também a alunas dos anos finais do Ensino Fundamental. Buscando disponibilizar conhecimento sobre a área de Informática, Computação e das Tecnologias da Informação e Comunicação. [Maciel e Bim, 2016].

Com principal intuito de motivá-las a seguirem carreiras nessas áreas, se preocupando também com a permanência delas nos cursos de graduação e com o empoderamento diante da carreira. O programa tornou-se muito conhecido desde seu surgimento, emergiram então iniciativas de outras instituições atuando como parceiras e multiplicadoras da mesma proposta disseminando essa ideia em grande parte do território nacional [Figueiredo, Neto e Maciel, 2016].

\section{Projeto Gurias Digitais}

Os cursos relacionados a área de Tecnologia da Informação (TI) estão, cada vez mais, sendo buscados devido à falta de profissionais especializados, entretanto, o número de mulheres neste ambiente é evidentemente abaixo do esperado. Diversas pesquisas apontam para a diminuição de mulheres matriculadas nesses cursos, causando assim, a falta da presença feminina no mercado de trabalho. 
Analisando então a realidade encontrada no curso de Ciência da Computação da Universidade Regional Integrada do Alto Uruguai e das Missões (URI Câmpus Santiago), assim como em muitos outros cursos no país, onde o número de mulheres que optam por iniciar o curso é considerado muito pequeno e esse número segue diminuindo, em alguns semestres sendo inexistente. Tendo em vista o número atual de alunos do curso citado, hoje as mulheres representam somente $13 \%$ do total de acadêmicos matriculados. Com isso, mostra-se necessária a implantação de um projeto que almeje aumentar a participação das mesmas.

Através do programa Meninas Digitais, projeto nacional que possui objetivos semelhantes aos desejados, surgiu a pretensão da criação de um projeto parceiro ao mesmo, como já vem ocorrendo em várias regiões do país. Com isso, o objetivo geral deste trabalho passou a ser desenvolver o Projeto Gurias Digitais, com o intuito de levar o aprendizado da lógica de programação para meninas que cursam os anos finais do ensino fundamental.

Assim, o projeto buscou incentivar o interesse das meninas pela área da Computação, mostrando que são capazes de desenvolver o que quiserem e realizarem isso como qualquer outro profissional, independente do seu gênero. Também servindo como veículo de comunicação, compartilhando informações e inspirando meninas e mulheres dentro do movimento. Buscando ainda inserir o tema "mulheres na TI" nas discussões de um ambiente escolar, criando um espaço de aprendizado e discussão, o qual passa-se a sistematizar e registrar ações e experiências desenvolvidas, promovendo também o envolvimento de diversos grupos de meninas/mulheres, incluindo graduadas, graduandas, professoras e demais estudantes em geral, dispostas a fazer parte do projeto. O projeto inclui levar o ensino de lógica de programação através da criação de jogos.

Levando em consideração o contexto mencionado, este projeto então buscou incentivar um grupo de meninas de uma escola municipal da cidade de Santiago (Rio Grande do Sul) a conhecerem um pouco mais a respeito do que se é abordado pela área de TI. Para possibilitar a criação do mesmo, foi necessário primeiramente a parceria entre o próprio curso de graduação citado e a Prefeitura Municipal, através da Secretaria Municipal de Educação e Cultura (SMEC) e da Secretária de Desenvolvimento Econômico (SMDE). Com isso, foi indicada pela SMEC a Escola Municipal de Ensino Fundamental Heron Jornada Ribeiro para aplicação do projeto.

A direção da escola recebeu o projeto com muito agradecimento por ter sido lembrada e também esperança de proporcionar a suas alunas um novo aprendizado e uma possível alternativa de futuro. Já quanto a turma, foi sugerido o $8^{\circ}$ ano, devido ao número de meninas que o cursam, das quais doze meninas aceitaram participar e duas outras meninas do $6^{\circ}$ ano também se mostraram interessadas. Ainda, a escola disponibilizou um professor para acompanhar o projeto e as meninas no trajeto escolauniversidade.

Devido ao laboratório da escola ser pequeno, conforme informado pela direção haveriam apenas sete computadores, dos quais muitos estavam em péssimas condições de uso, foi então definido que as aulas passariam a ser nas dependências da universidade, que cedeu o laboratório 432 para a realização das aulas do projeto. Assim, conforme disponibilidades da escola e do grupo de meninas, foi acordado que as aulas ocorreriam todas as quintas-feiras no laboratório da URI Câmpus Santiago. Sendo um 
total de 10 aulas, com uma hora de duração e mais 30 minutos livres, onde as meninas poderiam fazer uso dos computadores e Internet como desejassem.

Buscando a melhor forma de incentivar esse grupo de meninas, foi definido que seria então utilizado como objetivo do projeto a criação de um jogo que, inicialmente se pensou em ser mobile, mas como as meninas não teriam muitos conhecimentos necessários, optou-se em ser apenas um jogo para computador. Para que fosse possível então a criação do mesmo, foi necessário selecionar uma ferramenta que se enquadrasse no cenário apresentado.

Considerando o fato das meninas não possuírem nenhum conhecimento específico relacionados a criação de um jogo, o programa a ser utilizado no seu desenvolvimento necessitava ser simples, mas que mesmo assim possibilitasse a construção de um jogo completo e funcional, sem possuir como pré-requisito conhecimentos avançados em programação ou outra tecnologia.

Neste sentido, após uma longa pesquisa e teste das ferramentas, considerando os pontos positivos e negativos, optou-se pelo Game Maker, devido a sua interface simplificada a qual viabiliza uma abordagem intuitiva e ao mesmo tempo eficiente para a criação de jogos, conta com um sistema de "arraste e solte", o qual além de prover mais agilidade e facilidade, permite que qualquer pessoa desenvolva um jogo sem ter conhecimento algum de programação.

Dando início as aulas de desenvolvimento, foi apresentado as meninas a ferramenta e seus conceitos básicos, objetivando o desenvolvimento do jogo Breakout. Este jogo foi escolhido devido a sua simplicidade e por possuir o objetivo de "destruir todos os tijolos que se encontram no topo da tela, sem deixar a bola cair, para isso o jogador controla uma barreira, usada para rebater a bola" [Pimenta, 2018]. Assim, durante seu desenvolvimento foi possível explorar aspectos fundamentais em qualquer jogo, como por exemplo o deslocamento de objetos, destruição de um objeto da tela, limite e sentido de movimentos, entre outro.

Durante o decorrer do projeto, foram criadas todas as ferramentas e ações necessárias para o funcionamento do jogo, foram criadas Sprites e seus respectivos objetos, adição de som e a criação das telas do jogo, onde cada uma das participantes pode usar sua criatividade para a criação do seu próprio jogo.

\section{Conclusão}

As mulheres ainda acabam não sendo incentivadas a irem para a área de TI, pelo fato da computação ser considerada como masculina, e acabam então se afastando ou não obtendo interesse devido ao pré-conceito formado. Isso é uma realidade encontrada em todo o país, chamando a atenção de pesquisadores, empresas e até mesmos das universidades, onde as meninas são sempre minoria.

Então, buscou-se com este trabalho alterar essa realidade encontrada também na cidade de Santiago, através do desenvolvimento do projeto Gurias Digitais, o qual sempre teve por objetivo incentivar meninas a conhecerem melhor a Computação e pensarem nesta como uma opção, independentemente do seu gênero.

Após a execução do projeto, que contou com a participação de alunas da Escola Municipal Heron Jornada Ribeiro, realizando a criação do seu próprio jogo, ficou 
perceptível a necessidade de inserção da informática de modo geral no cenário escolar e principalmente meios de incentivo. Quanto a ferramenta Game Maker, a mesma se mostrou eficiente e as meninas conseguiram com o tempo realizar as ações necessárias antes mesmo da explicação da instrutora.

Ainda, conforme as respostas das participantes aos questionários realizados e análise do cenário, o projeto conseguiu alcançar seus objetivos, visto que contribui como veículo de comunicação, levando conhecimento e informações relacionadas a área computacional. E o principal, conseguiu mostrar a meninas de uma escola carente da cidade de Santiago, que elas são capazes de desenvolver e alcançar seus objetivos como qualquer aluno ou até profissional, independente do fato de serem mulheres, elas podem e devem optar pela área computacional.

\section{Referências}

Felitti, G. (2015). "Por que há menos mulheres no setor de tecnologia". Época Negócios. Disponível em: <epocanegocios.globo.com/Informacao/Dilemas/noticia/ 2015/08/por-que-ha-menos-mulheres-no-setor-de-tecnologia.html>. Acesso em: 20 jun. 2018.

Figueiredo, K., Neto, P. e Maciel, C. (2016). "Meninas Digitais Regional Mato Grosso: Práticas Motivacionais no Ensino Médio para a Equidade de Gêneros nas Carreiras e Cursos de Computação e Tecnologias". Anais do XXXVI Congresso da Sociedade Brasileira de Computação (CSBC 2016) - 10 Women in Information Technology (WIT 2016), p. 2702-2705.

Maciel, C. e Bim, S. (2016). "Programa Meninas Digitais - Ações para divulgar a Computação para meninas do ensino médio". Anais do Computer on the Beach, p. 327-336.

Oliveira, A. et al. (2016). "Você é o melhor menino desse grupo!". Anais do XXXVI Congresso da Sociedade Brasileira de Computação (CSBC 2016) - 10 Women in Information Technology (WIT 2016), p. 2746-2750.

Oliveira, A., Moro, M. e Prates, R. (2014) "Perfil Feminino em Computação: Análise Inicial". Anais do XXXIV Congresso da Sociedade Brasileira de Computação (CSBC 2014) - XXII Workshop de Educação em Computação, p. 1465-1674.

Pimenta, D. (2018). “Construa o jogo Breakout no Game Maker Studio". Udemy, Inc. Disponível em: <udemy.com/construa-o-jogo-breakout-no-game-maker-studio>. Acesso em: 17 nov. 2018. 